\title{
The role of the margins in the dynamics of an active ice stream
}

\author{
K. A. Echelmeyer, W. D. Harrison, C. Larsen and J. E. Mitchell \\ Geophysical Institute, University of Alaska-Fairbanks, Fairbanks, Alaska 99775-0800, U.S.A.
}

\begin{abstract}
A transverse profile of velocity was measured across Ice Stream B, West Antarctica, in order to determine the role of the margins in the force balance of an active ice stream. The profile extended from near the ice-stream center line, through a marginal shear zone and on to the slow-moving ice sheet. The velocity profile exhibits a high degree of shear deformation within a marginal zone, where intense, chaotic crevassing occurs. Detailed analysis of the profile, using analytical and numerical models of ice flow, leads to the following conclusions regarding the roles of the bed and the margins in ice-stream dynamics:
\end{abstract}

(i) The overall resistive drag on the ice stream is partitioned nearly equally between the margins and the bed and, thus, both are important in the force balance of the ice stream.

(ii) The ice within the chaotic zone must be about 10 times softer than the ice in the central part of the ice stream.

(iii) The average basal shear stress is $0.06 \times 10^{5} \mathrm{~Pa}$. This implies that the entire bed cannot be blanketed by the weak, deformable till observed by Engelhardt and others (1990) near the center of the ice stream - there must be regions of increased basal drag.

(iv) High strain rates and shear stresses in the marginal zones indicate that strain heating in the margins may be significant.

While the exact quantitative values leading to these conclusions are somewhat model and location-dependent, the overall conclusions are robust. As such, they are likely to have importance for ice-stream dynamics in general.

\section{INTRODUCTION}

The possible instability of the West Antarctic ice sheet has stimulated interest in its dynamics, especially in the role played by the ice streams which flow from the Siple Coast into the Ross Ice Shelf (e.g. Hughes, 1975). These ice streams are often highly crevassed and they move at speeds which are 2-3 orders of magnitude greater than the ice sheet in which they are embedded. In contrast to the fast-moving outlet glaciers and ice streams of Greenland (Clarke and Echelmeyer, 1989; Echelmeyer and others, 1991) and East Antarctica (McIntyre, 1985; Bentley, 1987), these Siple Coast ice streams do not generally lie in over-deepened bedrock troughs. Their thickness is on the order of $1000 \mathrm{~m}$, which is similar to that of the surrounding ice sheet (Shabtaie and others, 1987), and their surface slope is about $10^{-3}$. The resulting driving stresses are on the order of $0.1 \times 10^{5} \mathrm{~Pa}$. Such low driving stresses and surface speeds which are on the order of $1000 \mathrm{~m} \mathrm{a}^{-1}$ (e.g. Bentley, 1987; Whillans and others, 1987) imply that the resistance to flow is small compared to that normally found on ice sheets and non-surging valley glaciers.

Investigation of the controlling mechanisms for the flow of these ice streams has concentrated on basal processes. Seismic (Blankenship and others, 1987) and borehole studies (Engelhardt and others, 1990) in the vicinity of Upstream B Camp, about $300 \mathrm{~km}$ upstream of the grounding zone, have indicated that, locally, the bed of Ice Stream B consists of a weak, water-saturated till layer. The shear strength of this till layer is extremely low; measurements show it is on the order of $0.02 \times 10^{5} \mathrm{~Pa}$ (Kamb, 1991). These observations have led several authors to state or imply that the properties of this basal layer, and associated "sticky spots", are key to an understanding of ice-stream flow, and that basal drag is the ultimate controlling factor in ice-stream dynamics (see, for instance, Vornberger and Whillans, 1986; Whillans, 1987). However, some care must be taken in extrapolating these localized basal observations, which were made in a small and anomalously uncrevassed neighborhood of Upstream B Camp, to the remainder of Ice Stream B, which has a more highly crevassed surface. These crevasses may be indicative of other controlling mechanisms at play in ice-stream flow.

Studies on valley glaciers indicate that marginal drag at the valley walls is nearly equal in importance to basal drag as a controlling factor in glacier flow. However, on an ice stream such as Ice Stream B, the half-width is much greater than the depth (by about a factor of $15: 1$ at 


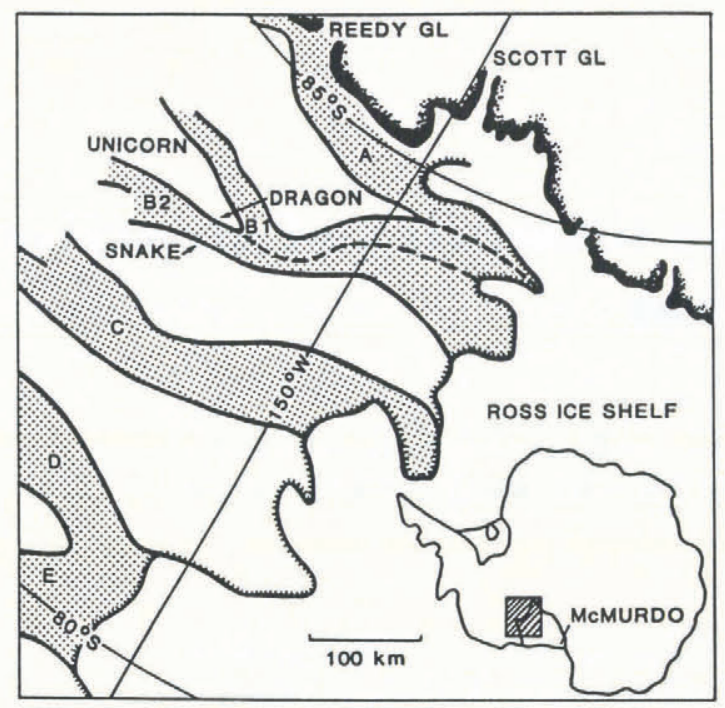

a

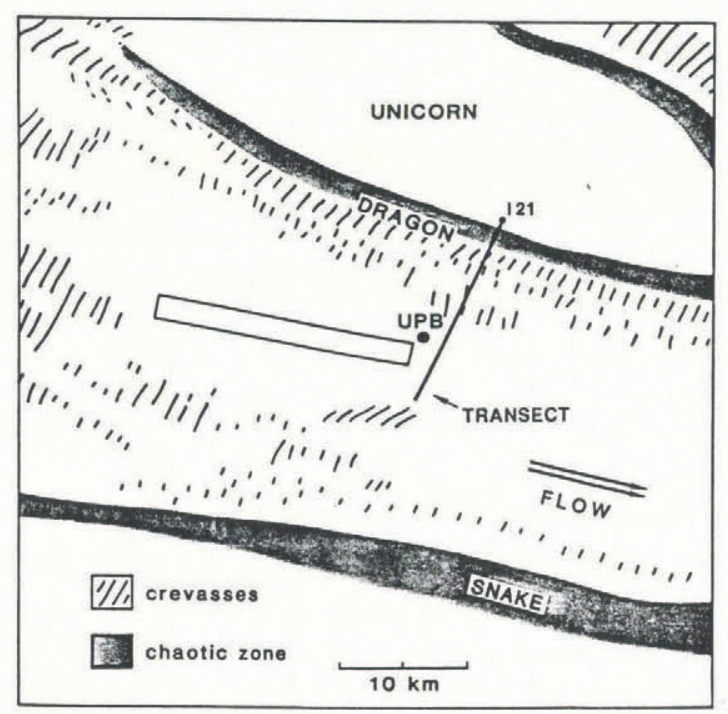

b

Fig. 1. (a) Location map, modified from Blankenship and others (1987) and Shabtaie and Bentley (1987). The triangles mark the sites of Upstream $B$ and Downstream $B$ camps. The ice streams are stippled and end at their grounding lines at the Ross Ice Shelf. (b) Location of velocity profiles. The rectangle indicates the site of the Ohio State University strain net (Whillans and others, 1987). The map is modified from Vornberger and Whillans (1986).

Upstream B Camp or 50:1 at Downstream B Camp (Fig. 1a), as opposed to about $3: 1$ for a valley glacier). Thus, the magnitude of marginal shear stresses on the West Antarctic ice streams must be nearly 10-50 times those at the bed in order to be important in the overall force balance of these ice streams.

In the limiting case of a glacier or ice stream which flows over a very weak, deformable bed, there must be a transfer of resistive forces from the bed to the margins and/or to longitudinal stress gradients. Such is the case for a floating ice shelf. Model results of MacAyeal (1989) show that marginal shear stresses and ice-shelf backpressure are important in determining the overall velocity field of the Siple Coast ice streams. In a second study, MacAyeal (1992) has used a velocity field determined from the motion of crevasses in the marginal zones of Ice Stream $\mathrm{E}$ to investigate the balance of forces along that ice stream. The velocity field obtained in this manner allows a direct investigation of marginal processes, as opposed to measurements made on crevasse-free regions. $\mathrm{He}$ again found that, while the existence of a deformable bed is important, the margins and ice-shelf back-pressure provide crucial controls on the flow.

Similar conclusions have been reached by Jackson (1991) on Ice Stream B. She used the motion of crevasses from repeat photography to determine the velocity field. Her results show that there exists important lateral shear across most of the ice stream in a region around Upstream $\mathrm{B}$ and, thus, concluded that marginal drag is an important control at that location. Whillans and others (1993) also argued for the importance of marginal drag on this ice stream using these data.

Frolich and Doake (1988) found that lateral shear stresses are important only in narrow zones at the margins of Rutford Ice Stream. Basal shear stresses dominate over much of the central region of the ice stream, even near the grounding zone. These conclusions are based upon surveyed velocity profiles which do not, in most cases, extend across the marginal shear zones because extensive crevassing prohibited travel there.

Another factor that is important is the rheology of ice within marginal zones. Hughes (1975) has suggested that there may be a substantial softening of the ice there. Such softening may occur because of the preferred fabric developed during the accumulation of large shear strains in the deformational history of marginal ice (Jacka and Budd, 1989). This enhanced flow within the margins may be important in determining the location and dynamics of ice streams.

In the present paper, we describe measurements made on Ice Stream B which are directed at the problem of the margins and their role in controlling ice-stream flow. Measurements of surface velocity were made along a transverse profile extending from near the center of the ice stream across the shear margin and into the slow-moving ice sheet. These observations are discussed in terms of flow models which indicate that the margins do play an important role in controlling ice-stream motion, with marginal drag being equal to or greater than basal drag at some locations. Inferences about the mean basal shear stress may be made from these models and a comparison with the strength of basal till from Upstream B as measured by Kamb (1991) is made. We also investigate the softening of ice within the marginal zones where the ice has a history of intense shearing and the viscous heating which is a consequence of the large strain rate and shear stress at the margins.

\section{MORPHOLOGY OF THE ICE STREAM ALONG THE TRANSVERSE PROFILE}

In December 1989, a transverse-velocity profile in the vicinity of Upstream B Camp was surveyed across a line extending from near the ice-stream center line (about $3.3 \mathrm{~km}$ north of Upstream B Camp), through the south shear margin (the "Dragon") and on to the relatively uncrevassed, slow-moving Unicorn (Fig. 1b). The ice 
- crevesses 网 chootio zone
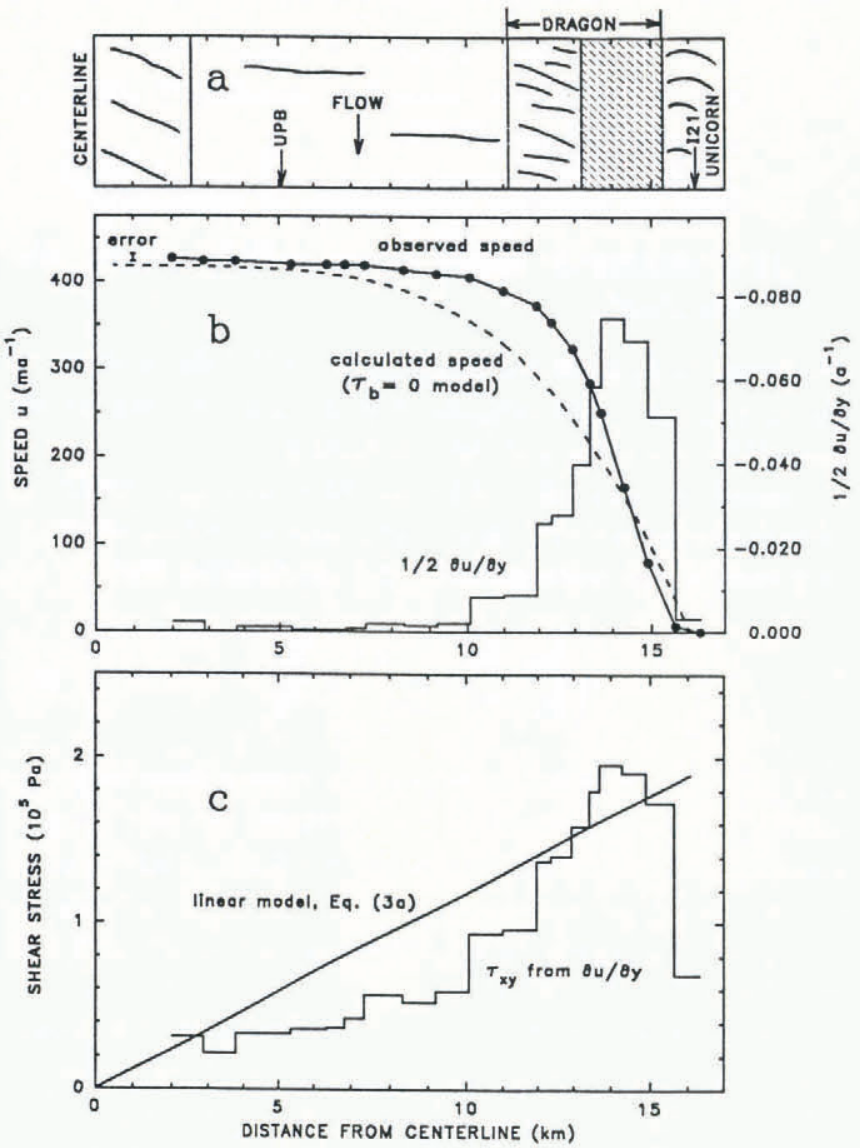

Fig. 2. Transverse profile. (a) Schematic diagram of the crevasse density and spacing across the section of Ice Stream $B$ crossed by the velocity profile. Approximate crevasse orientations are shown. (b) Longitudinal component of the horizontal surface velocity, $u$, and its transverse derivative, $\frac{1}{2} \partial u / \partial y$, along the line shown in Figure $1 b$. The dashed curve shows the velocity profile for a model in which the basal shear stress is zero. (c) Calculated transverse shear stress from Equation (2) and the simple linear model of Equation (3a).

stream is about $31 \mathrm{~km}$ wide at this location and the surveyed profile was $14.2 \mathrm{~km}$ in length. Near the north end of the profile (close to the ice-stream center line) there exists a zone of oblique crevassing of moderate density along a longitudinal topographic ridge $(20 \mathrm{~m}$ in elevation relative to Upstream B). The cause of these crevasses is not clear. From the base of the ridge, the profile cut across relatively uncrevassed ice near where the strain grid of Whillans and others (1987) was situated (Fig. 1b). There are almost no large crevasses over a stretch of about $8 \mathrm{~km}$, although there are small ones with a spacing of about 50 $100 \mathrm{~m}$ which have little surface expression in the way of linear depressions or visible cracks. About $11 \mathrm{~km}$ from the center line, the $4-5 \mathrm{~km}$ wide marginal shear zone (the "Dragon") is entered, as shown schematically in Figure 2a.

During a ski traverse of this shear zone in 1989, three distinct sub-zones were identified. On the ice-stream side there is a $2 \mathrm{~km}$ wide region of large but somewhat organized crevasses whose density increases toward the margin. These crevasses roughly trend upstream at an angle of $40-70^{\circ}$ to the margin, indicating an origin related to transverse shear. This sub-zone ends rather abruptly at the "chaotic" zone, which consists of highly disorganized crevasses and fractured ice blocks. Nearsurface conditions suggest that there is great void space at depth. This chaotic sub-zone is also about $2 \mathrm{~km}$ in width. Within this region, about $14.3 \mathrm{~km}$ from the center line, there was a $\frac{1}{3} \mathrm{~km}$ wide longitudinal furrow several meters deep. This furrow was not obvious during a traverse in 1992; it may not be a steady feature. The outer edge of the chaotic zone is marked by an abrupt boundary with the third sub-zone which consists of large but widely spaced $(50-100 \mathrm{~m})$ arcuate crevasses. The orientation of these outer crevasses also indicates an origin related to marginal shear, with some rotation superimposed (Vornberger and Whillans, 1990). These crevasses then pinch out in the slow-moving ice of the Unicorn, which is an "island" of slow-moving ice sheet between the two branches of Ice Stream B, labeled B1 and B2 in Figure la (following Vornberger and Whillans, 1986). The boundary between the chaotic zone and the Unicorn may be taken as the boundary between the ice stream and the non-streaming ice sheet. As will be seen below, each of the zones across the transverse profile can be identified with features found in the velocity and strain-rate profiles.

\section{VELOGITY THROUGH THE MARGIN}

Approximately 20 markers were placed along the transverse profile, including several in the highly crevassed "Dragon". The markers were surveyed three times at about $8 \mathrm{~d}$ intervals using a $1 \mathrm{~s}$ theodolite and an electronic distance meter. A retro-reflecting prism was mounted on each of the markers in the chaotic zone to avoid any reoccupation of these somewhat hazardous sites during the surveys.

Reduction of the survey data was accomplished by assuming that marker I21 (Whillans and others, 1987), which was situated at the end of our profile on the Unicorn, did not move. Such an assumption was necessary because of the lack of any absolute positioning at the time of the survey and by the geometry of the survey network. The geoceiver-survey results of I. Whillans (personal communication) during previous years indicate that marker I21 actually moves about $1 \mathrm{~m} \mathrm{a}^{-1}$ obliquely into the ice stream. This slightly nonzero velocity will cause our calculated velocities to be somewhat lower than the true ones. Errors arising from this assumption will affect the calculated velocity of each marker in a similar manner and this systematic error is included in the estimated error bounds on the velocity measurements which are $\pm 3-5 \mathrm{~m} \mathrm{a}^{-1}$. Velocities calculated over the two different time intervals between surveys agree within these error bounds. In the following analysis, we take the $x$ axis along the mean direction of flow, normal to the profile, the $y$ axis approximately along the profile, directed to the south, and $z$ upward.

The longitudinal component of surface velocity, $u$, resulting from these surveys is shown as a function of distance from the ice-stream center line in Figure 2b. Traversing outward from the center line, the speed shows a gradual decrease as one moves off the topographic ridge 
at the $2 \mathrm{~km}$ position. Across the uncrevassed part of the ice stream, the speed continues to show a slight decrease and, then, within the 4-5 km wide marginal shear zone the speed decreases rapidly to near-zero. Within the marginal zone, the small transverse component of velocity, $v$, (not shown here) is directed into the ice stream, as is typical of convergent flow. Between 13 and $14 \mathrm{~km}$, just in from the longitudinal furrow, the curvature of the velocity profile changes sign and the magnitude of the transverse gradient of the longitudinal velocity, $\partial u / \partial y$, reaches a maximum. Outward of this inflection point, the rate of decrease in speed is less than that found within most of the chaotic zone. The velocity profile is generally smooth but there are two significant jumps in $\partial u / \partial y$, which may be caused by measurement error or by a change in ice-flow properties, as discussed below.

The observed velocity profile is similar to that observed on valley glaciers, in which the half-width to center-line depth ratio is relatively large, say $4-5$. It is not reminiscent of true "plug flow" which has been observed on glaciers during surges (e.g. Kamb and others, 1985), because the speed is not constant in the center part of the profile and the marginal decrease is rapid but not extremely abrupt.

One-half of the transverse derivative of the longitudinal velocity, $\frac{1}{2} \partial u / \partial y$, is also shown in Figure $2 \mathrm{~b}$. The derivative has been calculated discretely between each of the markers. Because the markers are not uniformly spaced, the error in $\frac{1}{2} \partial u / \partial y$ varies somewhat, ranging from 0.001 to $0.005 \mathrm{a}^{-1}$. The velocity of several additional markers placed upstream of the transverse profile near and within the marginal zone shows that the longitudinal gradient of the transverse velocity, $\partial v / \partial x$, is small and thus $\frac{1}{2} \partial u / \partial y$ is approximately equal to the shear-strain rate, $\dot{\epsilon}_{x y}$.

The peak in the velocity gradient is centered in the chaotic zone, inside of the longitudinal furrow, not at the Unicorn-ice-stream boundary at $15 \mathrm{~km}$. The width of this peak corresponds to the width of the crevassed marginal shear zone, with heavy crevassing ending at shear-strain rates below about $0.005 \mathrm{a}^{-1}$. The chaotic crevassing occurs where the strain rate exceeds about $0.05 \mathrm{a}^{-1}$. The peak shear-strain rate is about $0.08 \mathrm{a}^{-1}$, a value similar to that found along the margins of some fast-moving valley glaciers.

\section{DISCUSSION}

There are several interesting features of the observed velocity profile which are possibly unique to ice-stream flow. First, the center-line velocity is large in comparison with the surrounding ice sheet. Secondly, the velocity decreases rapidly within the narrow chaotic zone. The velocity does not vary much over the central part of the ice stream but the profile is not one of plug flow. And, lastly, there is the inflection point between 13 and $14 \mathrm{~km}$, which is about $1.5 \mathrm{~km}$ into the ice stream from the contact between the ice stream and the relatively stagnant Unicorn.

In this section, we compare this profile with the velocity field obtained from analytical and numerical models of flow. The comparisons then allow us to address the following questions:
(1) What are the roles of the margins and of the bed in the force balance of the ice stream?

(2) How does the calculated basal shear stress compare with the measured strength of basal till samples (Kamb, 1991)?

(3) Does ice rheology vary across the ice stream?

(4) Is significant viscous heating likely within the margins?

We begin with a simplified estimate of the shear stress at the margin and of the importance of marginal drag on the overall force balance of the ice stream.

Based on our off-profile markers and the results of Whillans and others (1987) and Jackson (1991), we make the reasonable assumptions near the margins that

$$
\left(\frac{\partial u}{\partial x}, \frac{\partial v}{\partial x}, \frac{\partial v}{\partial y}\right) \ll \frac{\partial u}{\partial y}
$$

and that all gradients involving the vertical direction are small at the surface. For the purposes of this simple analysis, we assume that the strain rates are constant with depth. (In actuality, they may vary with depth because of changes in ice temperature, material properties and the basal boundary condition.)

Given these assumptions, a prediction of the shear stress $\tau_{x y}$ can be obtained from the power-law constitutive relation for ice $\left(\dot{\epsilon}=A \tau^{n}\right)$ where $\dot{\epsilon}$ and $\tau$ are the effective strain rate and effective stress, respectively, and from the strain rate, $\dot{\epsilon}_{x y}$, at the surface, shown in Figure $2 \mathrm{~b}$. We assume a flow-law exponent of $n=3$ and a representative temperature throughout the ice column of $-15^{\circ} \mathrm{C}$ (see Engelhardt and others, 1990). Using the value of the flow-law parameter $A$ given by Paterson (1981) as $9 \times 10^{-18} \mathrm{~Pa}^{-3} \mathrm{a}^{-1}$ at this temperature, the shear-stress distribution across the ice stream is given by

$$
\tau_{x y}=\left(\frac{1}{2 A} \frac{\partial u}{\partial y}\right)^{\frac{1}{3}}
$$

which is shown in Figure 2c. The maximum stress is about $2 \times 10^{5} \mathrm{~Pa}$, and it occurs in the chaotic zone.

A first estimate of the importance of the margins in the force balance of the ice stream may be obtained by comparing the total down-slope gravitational force acting on the ice stream $(=\rho g H W \sin \alpha$, where $H$ is the mean ice thickness $(1100 \mathrm{~m}), \sin \alpha=1.3 \times 10^{-3}$ and $W$ is the total width of the ice stream $(\sim 31 \mathrm{~km}))$ with the shear stress integrated over the margins. Taking a representative marginal shear stress as $1.7 \times 10^{5} \mathrm{~Pa}$ from Figure $2 \mathrm{c}$, the total drag along the edges of the ice stream is about $3.7 \times 10^{8} \mathrm{~N}$ per meter of length in the $x$ direction, while the total gravitational driving force is $4.0 \times 10^{8} \mathrm{~N}$ per meter of length. This suggests that the margins provide a large proportion of the total resistive force on the ice stream at this location. Basal drag (and, to a lesser extent, longitudinal forces) must provide the remainder.

The velocity and estimated shear stress shown in Figure 2 may be compared with those obtained by a simple model in which we assume there is no basal drag and that the ice stream is restrained entirely by friction at the rigid margins. We also assume that the speed at the 
margins is zero and that material properties are constant throughout. Then, the shear stress would vary linearly with distance $y$ out from the center (Nye, 1965):

$$
\tau_{x y}=\rho g y \sin \alpha
$$

and by Equation (2) the velocity is given by

$$
u(y)=\frac{1}{2} A(\rho g \sin \alpha)^{3}\left[\left(\frac{W}{2}\right)^{4}-y^{4}\right]
$$

where $\rho$ is the density of ice, $g$ is the acceleration of gravity and $\alpha$ is the surface slope. We use a slope of $1.3 \times 10^{-3}$ which is obtained by measurement along a 10 $20 \mathrm{~km}$ length of the surface-elevation map of Shabtaie and others (1987) and on the higher-resolution map of Retzlaff and others (1993). The peak stress occurring at the ice-stream-ice-sheet boundary is $1.8 \times 10^{5} \mathrm{~Pa}$, as shown in Figure 2c. The center-line velocity predicted from this zero basal shear-stress model is about $420 \mathrm{~m} \mathrm{a}^{-1}$, which is quite close to that observed. However, the shape of the predicted velocity profile does not resemble that observed, as shown in Figure 2b. The predicted profile is more rounded, without the abrupt decrease in velocity localized in the marginal zone. The inferred transverse shear stress is also not linear. These differences are related, in part, to the assumption of zero basal shear stress.

\section{Introduction of basal shear stress}

Blankenship and others (1987), Engelhardt and others (1990) and Kamb (1991) found that there is a layer of deformable till beneath the ice stream near Upstream B. This till has a finite shear strength of about $0.02 \times 10^{5} \mathrm{~Pa}$ and its thickness goes to zero in some areas, possibly placing bedrock in direct contact with the ice. This would imply that there is a distribution of non-zero basal shear stress, $\tau_{\mathrm{b}}(y)$. This stress will provide additional restraint to the ice stream and it will influence the surface-velocity field.

In this section, we seek, in an approximate manner, a distribution of $\tau_{\mathrm{b}}$ which leads to the observed velocity profile-both the center-line speed and the rapid decrease in speed which occurs in the margins. We note that

$$
\tau_{\mathrm{b}}(y) \geq 0
$$

for any physically correct model, i.e. the bed cannot pull the ice downstream. The imposition of any non-zero $\tau_{\mathrm{b}}$ satisfying Equation (4) will decrease the predicted centerline speed. The close match of center-line speeds with $\tau_{\mathrm{b}} \equiv 0$ implies that the ice must, in general, be softer than would be predicted by the assumed uniform $-15^{\circ} \mathrm{C}$ temperature. We shall see that this is indeed the case.

We begin by again noting that Equation (1) holds near Upstream B and thus longitudinal stress gradients will be neglected. The stress-equilibrium equation in the down-glacier direction $(x)$ is then given by

$$
\frac{\partial \tau_{x y}}{\partial y}+\frac{\partial \tau_{x z}}{\partial z}=-\rho g \sin \alpha .
$$

The ice stream is approximated by a slab of rectangular cross-section with uniform width $W$, thickness $H$ and surface slope $\alpha$, as given above. The $z$ axis is taken positive upward from the bed along the center line. Integrating Equation (5) over the ice thickness yields

$$
\tau_{\mathrm{d}}+\int_{0}^{H} \frac{\partial \tau_{x y}}{\partial y} \mathrm{~d} z=\tau_{\mathrm{b}}(y)
$$

where $\tau_{\mathrm{d}} \equiv \rho g H \sin \alpha=0.127 \times 10^{5} \mathrm{~Pa}$ is the driving stress, $\left.\tau_{\mathrm{b}} \equiv \tau_{x y}\right|_{z=0}$ and $\tau_{x z}(H)=0$.

As a first approximation, we assume $\partial \tau_{x y} / \partial y$ is independent of depth. This assumption will be relaxed in the numerical model discussed later. Then

$$
\tau_{\mathrm{d}}+H \frac{\partial \tau_{x y}}{\partial y}=\tau_{\mathrm{b}}(y) .
$$

The flow law of ice may be used to express the shear stress $\tau_{x y}$ in terms of the measured strain rate at the surface, again assuming Equation (1) holds. The general form of the flow law is, following Paterson (1981),

$$
\dot{\epsilon}_{i j}=E A \tau^{n-1} \tau_{i j}^{\prime}
$$

where $\dot{\epsilon}_{i j}$ and $\tau_{i j}^{\prime}$ are the components of the strain rate and deviatoric stress tensors, respectively, $\tau^{2}$ is the second invariant of the deviatoric stress tensor (the "effective stress") and the flow-law parameter $A$ is a function of temperature. We have also introduced an enhancement factor, $E$, which allows for the softening of ice due to factors such as the development of a preferred fabric in ice which has a history of strong shear or varying impurity content which are not incorporated in the temperaturedependence of $A$. In general, $E=E(y)$. We take $n=3$.

Under the assumptions detailed above, the only nonzero stress component near the surface is $\tau_{x y}$. Equation (8) can then be used to express $\tau_{x y}$ at the surface in a form similar to Equation (2). For the moment, we assume that ice temperature does not vary laterally. Then, Equation (7) can be written as

$$
\tau_{\mathrm{b}}(y)=\tau_{\mathrm{d}}+\frac{H}{A^{\frac{1}{3}}} \frac{\partial}{\partial y}\left[\frac{1}{E^{\frac{1}{3}}}\left(\frac{1}{2} \frac{\partial u}{\partial y}\right)^{\frac{1}{3}}\right]
$$

where $\frac{1}{2} \partial u / \partial y$ is given at the surface in Figure $2 \mathrm{~b}$.

If we assume that there is no variation in ice rheology across the ice stream, then the enhancement factor is constant and can be taken equal to 1. Any overall softening of the ice can be incorporated into the constant $A$. Such softening may be due to an error of our assumption about the mean temperature for the ice or some uniform softening related to the strain history of all the ice within the ice stream, which would lead to an error if Paterson's (1981) values were assumed.

Taking the bulk ice temperature as $-15^{\circ} \mathrm{C}$ and the value of $A$ given by Paterson (1981) at this temperature, Equation (9) leads to negative basal shear stresses over much of the bed. This physically unrealistic result is to be expected, as explained above. Increasing $A$ by a factor of 10 still produces negative $\tau_{\mathrm{b}}$ in the chaotic zone, where the curvature of the velocity profile is large. Increasing $A$ by a factor of 10 is equivalent to assuming all of the ice within the stream is close to the melting point.

If we increase $A$ by a factor of 100 , then $\tau_{\mathrm{b}}$ inferred from Equation (9) is generally positive and, except near the margin, in the range $0-0.1 \times 10^{5} \mathrm{~Pa}$. However, there are still areas in the chaotic zone where the calculated $\tau_{\mathrm{b}}$ is slightly negative and $A$ would have to be increased 
further in order to eliminate all negative values of $\tau_{\mathrm{b}}$.

The basal shear-stress distributions for each of the assumed values of $A$ all lead to a value $\tau_{\mathrm{b}}$ which is relatively constant at about $0.05 \times 10^{5} \mathrm{~Pa}$ over the first $10 \mathrm{~km}$ of the bed out from the center. Some variation about this value is found where the increased flow occurs off the longitudinal ridge near the ice-stream center line described earlier. This is reasonable, since the assumptions inherent to the model of uniform thickness and surface slope are not met there. This feature of $\tau_{\mathrm{b}}(y)$ may be taken to imply that basal conditions do not vary greatly over the first $10 \mathrm{~km}$, at least as seen by the $1100 \mathrm{~m}$ thick filter of the ice stream. Variations over short distances across the bed could occur but the surfacevelocity field would not reflect them.

The overall conclusion reached from these models is that, unless the ice rheology is substantially (two orders of magnitude or more) different than that published (e.g. Paterson, 1981), there is no physically reasonable distribution of $\tau_{\mathrm{b}}$ which can explain the observed velocity field when the ice rheology is taken to be uniform across the ice stream. The simple model described does have several assumptions which may not be strictly valid but, as will be seen below, relaxation of some of them in a numerical model does not change this conclusion.

\section{Lateral variation of rheological properties}

The ice in the marginal zones has been subjected to a history of rapid shear strain. The total strain which a parcel of marginal ice has undergone is dependent upon its time of transit through the marginal zone and on the stability of the margin. Taking the zone of intense shear to be about $2 \mathrm{~km}$ in width and $v \sim 2-10 \mathrm{~m} \mathrm{a}^{-1}$, the transit time is on the order of $200-1000$ years. From Figure $2 b$, we see that the ice experiences an average rate of shear strain equal to about $0.04 \mathrm{a}^{-1}$ and, thus, the total accumulated strain could be extremely large. Hughes (1975) suggested that ice undergoing such accumulated shear strain could be weaker than unstrained ice. According to Jacka and Budd (1989), an enhancement factor $E$ equal to 8 occurs when the accumulated shear strain reaches 0.15 . Beyond that total strain, there appears to be no further increase in $E$. However, the extrapolation of this asymptotic value to the large strain accumulated during the few hundred year long passage through the shear margin may not be strictly valid and the resulting value of $E$ could possibly be larger. In addition, ice temperatures may be elevated in the marginal zones, because of viscous heating (Echelmeyer and others, 1992) which would further soften the ice. Such a lateral variation in ice-flow properties might lead to profiles of velocity and strain rate similar to those observed.

Equation (9) may be used to investigate this possibility. We are again subject to the assumptions leading to this equation. We again take the temperature to be constant at $-15^{\circ} \mathrm{C}$ and use the value of $A$ given by Paterson (1981) at this temperature. $\tau_{\mathrm{b}}$ is now taken to be constant and $E$ is a function of position across the ice stream, $y$. The variable $E$ will encompass fabric development, strain heating and possibly other sources of enhanced flow.
Integration of Equation (9) over $y$ from the center line outward gives

$$
E(y)=\left.\frac{1}{A} \frac{1}{\left(\tau_{\mathrm{d}}-\tau_{\mathrm{b}}\right)^{3}}\left(\frac{H}{y}\right)^{3} \frac{1}{2} \frac{\partial u}{\partial y}\right|_{y}
$$

where we have used the condition that $\partial u / \partial y=0$ at the center line because the channel is symmetric. Assuming that ice near the center line has "standard" flow properties, or $E(0)=1$, we obtain $\tau_{\mathrm{b}}$ from the limit

$$
\tau_{\mathrm{b}}=\tau_{\mathrm{d}}+\frac{H}{A^{\frac{1}{3}}} \lim _{y \rightarrow 0}\left[\frac{\left(\frac{1}{2} \frac{\partial u}{\partial y}\right)^{\frac{1}{3}}}{y}\right] .
$$

Extrapolating a smooth curve drawn through a plot of the quantity in the brackets of Equation (11) yields $\tau_{\mathrm{b}}$. (The plot is somewhat noisy due to the observed flow off the center-line ridge, as mentioned above.) This limiting value gives

$$
\tau_{\mathrm{b}} \approx 0.06 \times 10^{5} \mathrm{~Pa} .
$$

Using this value of $\tau_{\mathrm{b}}$ in Equation (10) yields the distribution of the enhancement factor $E$ shown in Figure $3 \mathrm{~b}$. The discontinuous distribution of $E$ is due to the discrete nature of the velocity data and measurement errors in $u$. Subject to the usual qualifications regarding anomalous flow induced by the center-line ridge (shown by the dotted line in Figure $3 \mathrm{~b}$ ), the results indicate that $E$ is nearly constant over the first $10 \mathrm{~km}$. There is then a softening of the ice at a position corresponding to the start of the crevassed Dragon. This softening reaches a peak $(E \sim 14)$ in the chaotic zone where shear-strain rates are the largest. Toward the Unicorn, the ice then again becomes stiffer.

These values of the enhancement factor in the chaotic zone are somewhat greater than, but consistent with, those obtained by Jacka and Budd (1989) in the laboratory for ice with a prolonged history of shear strain. The smaller values of $E$ outside the chaotic zone $(E \sim 3-5)$ are also consistent with their results, given the

a

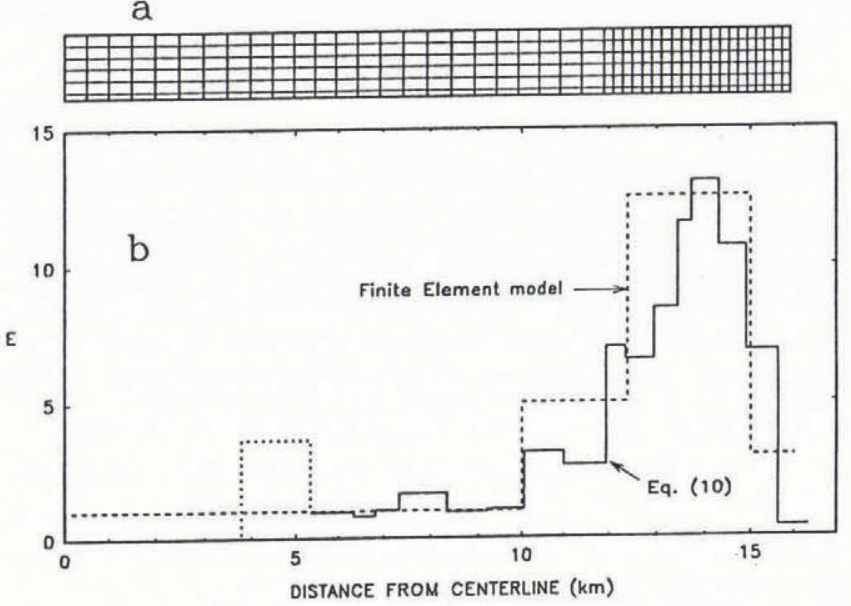

Fig. 3. (a) Finite-element grid used in model calculations. The thickness of the basal layer is exaggerated for clarity. (b) Enhancement factors from Equation (10) (solid line) and those used in the finite-element model (dashed) along the Upstream B profile. 
picture of smaller strain rates and smaller total strain in these regions.

If a somewhat warmer bulk-ice temperature were assumed, the base value of $A$ would increase. This would change the numerical values shown in Figure $3 \mathrm{~b}$ but the pattern of variation would not change. A ten-fold increase in $A$ (to that of near-temperate ice) would cause a transfer of some of the resistive drag to the bed and $\tau_{\mathrm{b}}$ from Equation (11) would increase to about $0.09 \times$ $10^{5} \mathrm{~Pa}$.

In summary, these simplified models indicate that there is no reasonable distribution of basal shear stress which can, by itself, explain the observed velocity profile. A picture which is consistent with the observations is as follows: nearly constant ice and bed properties out to $10 \mathrm{~km}$, an approximate ten-fold softening of ice within the crevassed Dragon and somewhat stiffer ice and/or an increase in basal drag within the marginal part of the Unicorn. A basal shear stress of about $0.06 \times 10^{5} \mathrm{~Pa}$ over much of the bed results from this picture. This value is greater than the $0.02 \times 10^{5} \mathrm{~Pa}$ measured by $\mathrm{Kamb}$ (1991) in the laboratory. This larger value may be explained by postulating a distribution of weak, deformable till and bedrock protrusions or less-deformable till along the bed.

Of course, these models may not be unique. It is likely that there is some combination of laterally varying ice properties and basal drag which also lead to the observed velocity profile. What is important is that the resulting model matches the observed profile and not just the speed at a few points near the center line.

\section{Finite-element analysis}

In order to relax some of the assumptions and provide a more realistic estimate of the degree to which the margins help support the ice stream, we have conducted finiteelement analysis of flow within a cross-section of a simplified ice-stream channel. The modeling scheme allows for flow in three dimensions within a twodimensional cross-sectional grid. The three-dimensional stress-equilibrium equations are solved at each point in the grid. Stress and velocity gradients in $x$, which are directed out of the plane of the cross-section (in other words, longitudinal gradients along the ice stream) are taken to be zero. The power-law $(n=3)$ constitutive relation (Equation (8)) for incompressible flow is used with a spatially variable flow-law parameter, $A(y, z)$. This allows us to account for temperature variation within the grid, as well as a spatially variable enhancement factor. Density is taken to be constant. (See Echelmeyer (1983) for details of the numerical algorithm.)

Because the exact cross-sectional shape of Ice Stream B along our profile is not known, we assume a simple rectangular cross-section $32 \mathrm{~km}$ wide with vertical sides positioned at the ice-stream-ice-sheet boundaries, a transversely horizontal surface and a total depth of $1100 \mathrm{~m}$ (Fig. 3a). This rectangular channel very closely approximates the depth profile measured by Shabtaie and Bentley (1988) at a nearby location on this ice stream, with variations from a rectangle being at most $10 \%$ near the center line and less elsewhere. Because the channel is assumed to be symmetric about the center line, we model only half of the cross-section. A grid of 264 quadrilateral isoparametric elements with linear shape functions was used (Fig. 3a). Clearly, some of the details of the observed velocity profile, such as the flow induced by the topographic ridge near the center, will not be modeled using such a simplified cross-section, but many of the essential features should be apparent.

A surface slope of $1.3 \times 10^{-3}$ is used. Symmetry requires that the tangential shear stress and transverse velocity are zero down the center line. The outer margin of the channel is taken to be vertical and the velocity there is set equal to zero to approximate the no-slip interface with the stagnant ice of the Unicorn. There is no direct evidence that the ice-stream margin does not extend vertically down to the bed, although warmer ice near the bed may cause some tilting of this boundary at depth.

As described earlier, Blankenship and others (1987), Engelhardt and others (1990) and Kamb (1991) have found a thin $(\leq 10 \mathrm{~m})$ layer of deformable till at the base of the ice stream near Upstream B. We incorporate this layer into our model by including a single layer of thin elements at the bed (Fig. 3a). Their thickness is included in the $1100 \mathrm{~m}$ total thickness stated above. A condition of no-slip is applied between the ice and the till, and at the bottom of the till. The rheology of the basal layer is assumed to follow the $n=3$ power law for convenience. Model results do not depend strongly on this assumed constitutive relation. The variable flow-law parameter $A(y, z)$ for this basal layer can be changed to simulate warm or cold ice, or a weak, deformable till. The layer thickness is taken to be $50 \mathrm{~m}$ in the final model in order to improve the accuracy of the stress calculations by keeping the aspect ratio of the thin elements relatively small. Tests were also done with a $10 \mathrm{~m}$ thick basal layer. Surface velocity and marginal stresses were not influenced by this change in layer thickness as long as the value of $A$ in the bottom layer was adjusted suitably. Calculation of the basal shear stress required care when smoothing through the centroid of the elements in the $10 \mathrm{~m}$ thick layer but the final values did not appear to differ significantly from those found using the more accurate $50 \mathrm{~m}$ thick elements.

The flow-law parameter was adjusted in accordance with ice temperature. It is probable that marginal temperatures may be elevated because of viscous heating (Echelmeyer and others, 1992) but we assume that the ice temperature measured in a borehole drilled at Upstream B Camp (Engelhardt and others, 1990) holds across the ice stream. We thus assume only a vertical variation in temperature, $T=T(z)$. The measured temperature profile is approximated by a simple four-layer model, with layers at the following depths: $0-400 \mathrm{~m}$ at $-24^{\circ} \mathrm{C}$, $400-800 \mathrm{~m}$ at $-20^{\circ} \mathrm{C}, 800-1050 \mathrm{~m}$ at $-9^{\circ} \mathrm{C}$ and the basal layer at the melting point. The temperature-dependent flow-law parameter, $A(z)$, is taken from Paterson (1981). A spatially variable enhancement factor, $E(y, z)$ (Equation (8)), is introduced. This factor is again used to specify the softening of ice due to the combined effects of prolonged shear strain (Jacka and Budd, 1989), elevated marginal ice temperatures and other factors. Knowledge of the specific source of the enhanced flow is not required. An enhancement factor is also introduced in the basal 
layer to allow lateral variations in its strength and in the basal shear stress.

Guided by the analytical results discussed above, several finite-element models of increasing complexity were run in order to illustrate the controlling mechanisms implied by the observed surface-velocity profile. Key features of the observed profile which must be fitted by any successful model include: the magnitude of the velocity at Upstream B Camp $\left(420 \mathrm{~m} \mathrm{a}^{-1}\right)$, the decrease in speed over the reach from 8 to $12 \mathrm{~km}$, the rapid decrease and associated peak in strain rate in the chaotic zone, reverse curvature of the profile as the Unicorn is approached, and nearly zero speed in the Unicorn.

Basic models confirm the analytical results. In one numerical model, the properties of the deformable basal layer were adjusted to make the basal shear stress equal to the shear strength of the till as measured by Kamb (1991) at Upstream $\mathrm{B}\left(0.02 \times 10^{5} \mathrm{~Pa}\right)$ and $E$ set equal to 1 everywhere (no enhancement). In this case, the calculated center-line speed is only about half that observed and the resulting velocity profile differs significantly from that observed. It was instead more rounded, like that shown by the dashed profile in Figure $2 b$, but of reduced magnitude. In another model, $E$ was chosen to approximate that calculated from Equation (10) and shown in Figure 3a. Properties of the basal layer were adjusted to fix $\tau_{\mathrm{b}}$ at Kamb's (1991) value of shear strength. The resulting surface speed was too large and the shape of the profile again differed from that observed.

An attempt was made to find a distribution of $\tau_{\mathrm{b}}$ (or, equivalently, $A$ in the basal layer) which would reproduce the observed velocity without requiring a lateral variation in $E$ within the ice. The result was similar to that found analytically: no physically reasonable basal shear stress with acceptable but laterally uniform ice rheology could be found which yields the shape and magnitude of the observed velocity.

Thus, we are led to the following conclusions: some, but not all, of the ice within the cross-section must be softened, and there must be a weak deformable layer over much of the bed. The strength of this basal layer must, on average, be somewhat greater than that observed locally at Upstream B.

An exhaustive search for the distribution of material properties which yield the best fit to the observed velocity profile has not been attempted, nor can it be without adequate knowledge of englacial temperatures, accurate ice depths and the incorporation of longitudinal-stress gradients. However, we present a model (labeled "model A"), which displays all of the critical features of the observed velocity distribution and gives us substantial insight into the role of the bed and of the margins in controlling the flow of Ice Stream B.

Enhancement factors in the ice are given by the dashed line in Figure 3b. They approximate those determined using Equation (10) and their magnitude is reasonable given both the ideas of Jacka and Budd (1989) and the expected elevation of ice temperature in the margins as detailed below. The flow-law parameter in the weak basal layer is adjusted to match the surface velocity at Upstream B; it is taken to be constant across the bed in this model.

The resulting velocity profile is shown by the dashed curve in Figure 4. There is close agreement with the observations (large dots). The calculated strain rate also compares well with that observed (Fig. 4). While this model is non-unique and simplified, the close agreement between model and observations, along with our search through "parameter" space in which $E(y, z)$ and $\tau_{\mathrm{b}}(y)$ were varied, lead to some general conclusions which are robust.

First, flow properties of the ice and basal layer (or, equivalently, $E$ and $\tau_{\mathrm{b}}$ ) must be fairly constant over the first $10 \mathrm{~km}$ of the profile outward from the center line. Secondly, there must be a weak layer at the bed in order to match the center-line velocity-no amount of softening at the margins can lead to this speed. Thirdly, there must be soft ice in the marginal zones. If there is no softening, then the resulting velocity profile is much more rounded than that observed and there is no localized peak

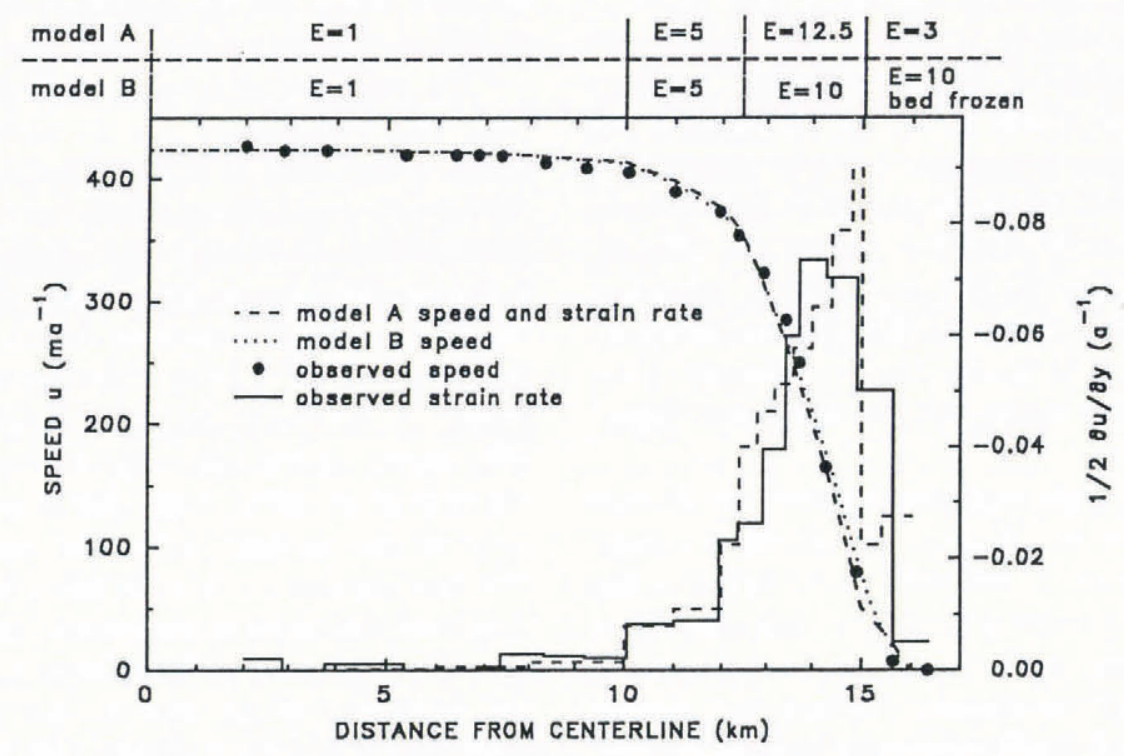

Fig. 4. Final flow models versus observed speed. Enhancement factors for model A (stiffer ice at margins; solid line) and model $B$ (bed frozen at margins; dashed) are shown at the top of the figure. Observed and modeled transverse strain rates (righthand axis) are also shown. 
in shear-strain rate. No distribution of basal-till properties (or $\tau_{\mathrm{b}}$ ) can produce such a profile by itself. We have taken the bed properties to be constant across the ice stream. This leads to an increase in $E$ from 1 to 5 in a region encompassing the transition from the relatively uncrevassed ice stream to the Dragon $(8-12+\mathrm{km})$, followed by an increase to $E=12.5$ in the chaotic zone and then a drop to $E=3$ in the region of the Dragon-Unicorn boundary. A more continuous variation in $E$ might be expected physically, although the abrupt steps in the observed strain rate may indicate a discrete nature to the variation.

In our model, the basal shear stress is about $0.06 \times$ $10^{5} \mathrm{~Pa}$ away from the margins. This is similar to that obtained from Equation (11) and it is 3-4 times greater than the shear strength of the basal till layer sampled by Engelhardt and others (1990). Because the center-line speed is so closely linked to $\tau_{\mathrm{b}}$ near the center, this again implies that the entire bed cannot be blanketed by a layer as weak as the samples indicate. There must be a distribution of weak and stiff regions at the bed. For example, if we assume that till in the layer has a strength of $0.02 \times 10^{5} \mathrm{~Pa}$ and that this till is interspersed with "sticky spots" (following Van der Veen and Whillans, 1989), where the basal shear stress is, say, $0.5 \times 10^{5} \mathrm{~Pa}$, then the area fraction of "sticky spots" would be about 0.08 , weak till thus covering $92 \%$ of the bed. Realistically, there must be some more continuous distribution of basal drag, ranging from that of weak till to bedrock protuberances. On average, an increase in basal drag as the margin is approached might also satisfy this requirement for a stiffer basal layer.

The non-uniquess of the model described above is illustrated by the following result. The inflection point within the marginal zone of the velocity profile can be modeled equally as well by imposing a frozen, nonrapidly deforming bed beneath the outer $1 \mathrm{~km}$ of the marginal zone (where $T=-1^{\circ} \mathrm{C}, E=1$ ), while $E=10$ in the ice above this basal layer (shown by the dotted line in Figure 4, model B). This is in lieu of prescribing a column of stiffer ice $(E=5)$ within this outer sub-zone of the margin as was shown in Figure $3 \mathrm{~b}$ and in model $\mathrm{A}$. Such a stiff basal layer is compatible with the scenario in which the margin of the ice stream signifies a change from a stiff bed beneath the slow-moving ice sheet to a deformable water-saturated basal layer beneath the faster-moving ice stream.

The effective shear stress $\left(\tau=\left(\tau^{2}{ }_{x y}+\tau^{2}{ }_{x z}\right)^{\frac{1}{2}}\right)$ within the ice stream for model $\mathrm{A}$ is shown in Figure 5. Away from the bed $\tau \approx \tau_{x y}$, while near the bed $\tau_{x z}$ becomes a significant component of $\tau$. Numerical values of $\tau_{x z}$ indicate that the marginal shear stress approaches $1.2 \times 10^{5} \mathrm{~Pa}$ and the average basal shear stress is about $0.06 \times 10^{5} \mathrm{~Pa}$. Integration of the basal shear stress across the total width of the ice stream gives $1.7 \times 10^{8} \mathrm{~N} \mathrm{~m}^{-1}$, while vertical integration of the shear stress down the two margins (assumed symmetric) yields a total marginal drag force of $2.3 \times 10^{8} \mathrm{~N}$ per meter of length. Thus, the margins provide $58 \%$ and the bed supplies $42 \%$ of the total resistive drag required for equilibrium of the ice stream at Upstream B. Similar results apply for model B, except there is increased basal drag near the margins, as expected.
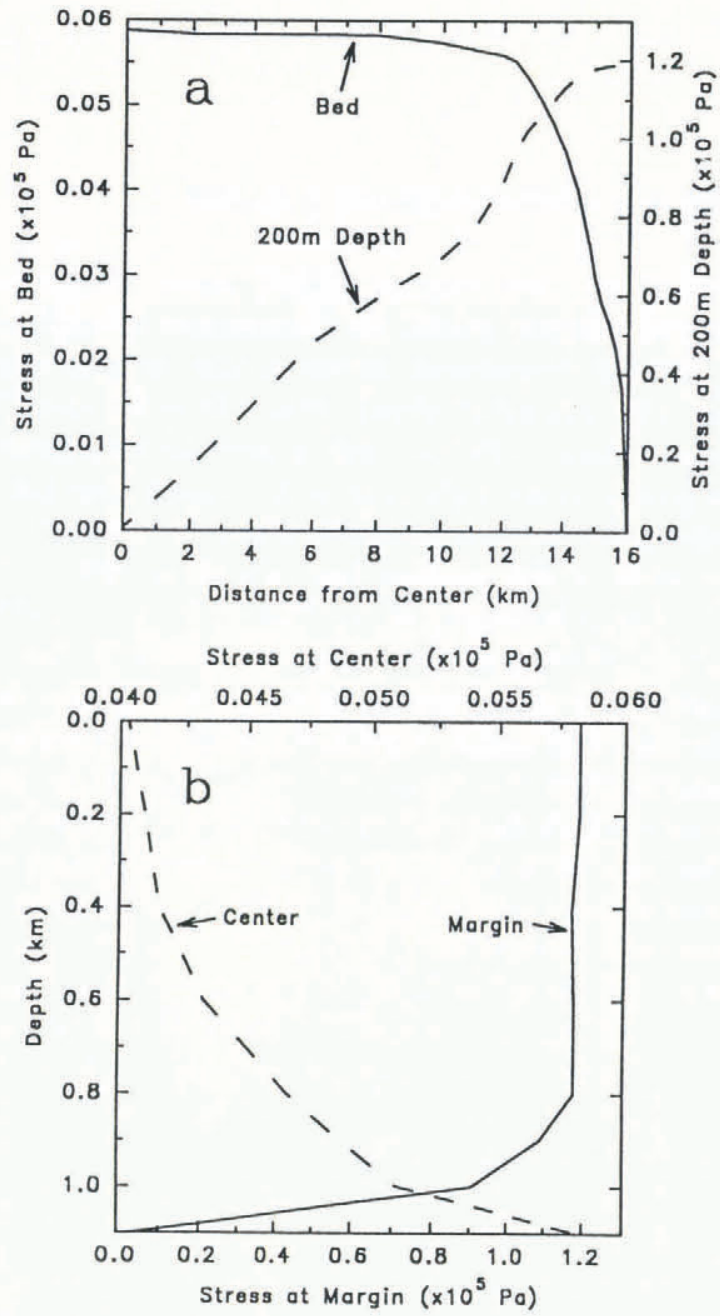

Fig. 5. (a) Smoothed horizontal profiles of $\tau$, the effective shear stress $\left(=\left(\tau_{x z}{ }^{2}+\tau_{x y}{ }^{2}\right)^{\frac{1}{2}}\right)$ across the ice stream at a depth of $200 \mathrm{~m}$ and along the bed. Lefthand axis corresponds to profile along bed (solid line), the righthand to the profile across at a depth of $200 \mathrm{~m}$ (dashed). (b) Smoothed vertical profiles of $\tau$ down the margin (lower axis, solid) and at position $0.5 \mathrm{~km}$ in from the center line (upper axis, dashed). These curves represent smoothed versions of the actual model results which are affected by discretization and interpolation noise.

Again, we note that this is only an illustrative example for one region of an active ice stream. Ice temperatures throughout the cross-section are not known, nor is the exact depth profile. Ambiguity in the surface slope also precludes a more exact treatment. If the surface slope quoted by Alley and others (1987; $\alpha=2.7 \times 10^{-3}$ versus our value of $1.3 \times 10^{-3}$ ) is used, then the mean basal shear stress is about $0.17 \times 10^{5} \mathrm{kPa}$, that at the margins is $1.3 \times 10^{5} \mathrm{kPa}$, and the resistive force of the margins drops to about one-third the total drag required to balance the increased driving force. Thus, while the ratio of basal to marginal drag may vary somewhat, the basic conclusion that the margins are important in the force balance at Upstream B remains.

If the marginal zones are not vertical but instead slope inward, mimicking typical "valley walls", then the amount of softening in the marginal ice need not be as great. Similarly, since the actual ice-stream channel is not exactly rectangular in shape (Shabtaie and Bentley, 
1987), the enhancement factor in the basal layer need not be as large.

\section{FLOW AT DOWNSTREAM B GAMP}

Bindschadler and others (1987) have measured a transverse-velocity profile at Downstream B approximately $240 \mathrm{~km}$ downstream of our profile. It also extends across the marginal shear zone. Downstream B is relatively close to the grounding zone and longitudinal stress gradients are important in the overall force balance (Bindschadler and others, 1987). The ice stream is nearly $86 \mathrm{~km}$ wide at this location but only about $800 \mathrm{~m}$ thick. The southern boundary of Ice Stream B is the northern boundary of the slower-moving Ice Stream A and thus the geometry of marginal forces is not likely to be symmetric. The surface slope is much less at Downstream $\mathrm{B}$, ranging from 0 to $0.4 \times 10^{-3}$ depending on the length scale over which the gradient is determined (Bindschadler and others, 1987). In the following, we use the large-scale average of $0.4 \times 10^{-3}$ in our calculations, realizing that it represents an upper bound.

We have modeled the flow in a cross-section (again taken to be rectangular; $800 \mathrm{~m}$ deep and $43 \mathrm{~km}$ halfwidth). The important longitudinal stress gradients have been neglected - we are again interested in the relative importance of basal to marginal drag and we do not expect their ratio to depend too strongly on the longitudinal stress gradients just as the ratio does not depend strongly on surface slope. The temperature profile observed at Upstream B has been scaled to $800 \mathrm{~m}$ depth and the shear-zone width has been adjusted to fit that observed. No attempt was made to match accurately the observed velocity profile because of the relative sparseness of data and relatively large scatter in the published speeds within the critical marginal shear zone. The agreement between the observed (Bindschadler and others, 1987) and modeled profiles at Downstream B, shown in Figure 6 , is therefore not as close at that found at Upstream B but it still is quite good. The enhancement factors used for this model are shown along the top of Figure 6 . They are similar to those found at Upstream B.

Marginal shear stresses are about $0.8 \times 10^{5} \mathrm{~Pa}$, while

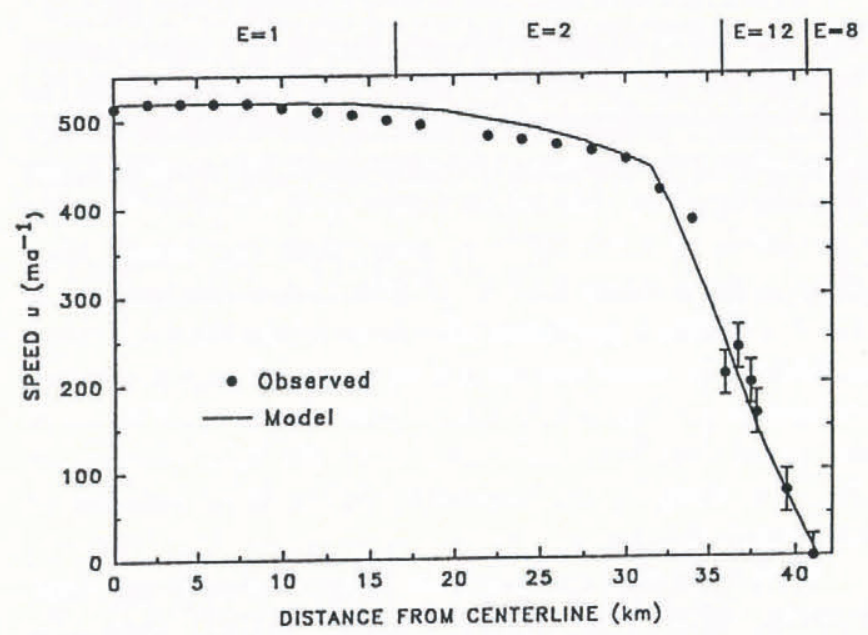

Fig. 6. Modeled and observed surface speed across $a$ profile at Downstream B. Observed speed is taken from Bindschadler and others (1987). the mean basal shear stress is about $0.014 \times 10^{5} \mathrm{~Pa}$. Integration of the model shear stress over the width of the bed gives $1.1 \times 10^{8} \mathrm{Nm}^{-1}$, while integration down the two margins yields $1.2 \times 10^{8} \mathrm{~N} \mathrm{~m}^{-1}$. This indicates that at Downstream $B$ the total marginal drag force is again nearly equal to the total basal drag. The strength of a deformable bed, if it exists at Downstream B, must be less than that observed at Upstream B, and less than that quoted by Kamb (1991). This makes sense, because the ice stream must be near flotation this close to the grounding zone. Pore-water pressure in any deformable layer must be high and "sticky spots" must be few and far between. The fit to the observed velocity profile could be improved if the basal drag increased outward to the margins, but then basal drag near the center line would be even less. If the smaller average value of local surface slope is pertinent to the flow here, then the importance of the margins will increase as will the importance of longitudinal stress gradients.

\section{VISCOUS-HEAT DISSIPATION IN THE MARGINS}

The high shear-strain rates and shear stresses found in the margins will give rise to substantial viscous-heat dissipation in these narrow zones. This heating will be limited by the advection of cold ice moving into the ice stream from the sides. The amount of heating under steady-state conditions is readily estimated. Making the plausible assumptions that horizontal and longitudinal conduction and longitudinal advection are small, the governing twodimensional advection-diffusion equation in the margins is given by

$$
\kappa \frac{\partial^{2} T}{\partial z^{2}}-\dot{b}(1-z / H) \frac{\partial T}{\partial z}-v \frac{\partial T}{\partial y}+\frac{2 \dot{\epsilon}_{x y} \tau_{x y}}{\rho c}=0
$$

where $T$ is the temperature, $\kappa$ is the thermal diffusivity, $\dot{b}$ is the accumulation rate (ice equivalent) at the surface and $\rho c$ is the volumetric heat capacity. Here, $y$ is the transverse horizontal coordinate measured inward from the outer edge of the margin and $z$ is the coordinate measured downward from the surface. We take the vertical velocity to vary linearly with depth. The vertical temperature profile outside the margin is taken to be the one which results from Equation (13) with the third and fourth terms zero, and a constant basal temperature gradient; these boundary conditions are assumed to be maintained within the margin. The transverse velocity, $v$, and $\dot{\epsilon}_{x y} \tau_{x y}$ are taken to be constant at the mean values observed or calculated at the ice stream-Unicorn boundary. Thus, $2 \dot{\epsilon}_{x y} \tau_{x y} \approx 10^{-3} \mathrm{Wm}^{-3}$, and $v=1-10 \mathrm{~m} \mathrm{a}^{-1}$ (Whillans and others, 1987). The numerical solution for $v=5 \mathrm{~m} \mathrm{a}^{-1}$ is shown in Figure 7 as a function of distance $y$ in from the margin, or, equivalently, time $t=y / v$. It can be seen from Equation (13), or from Figure 7, that at depths sufficient for surface effects to be negligible

$$
\Delta T \approx \frac{2 \dot{\epsilon}_{x y} \tau_{x y}}{\rho c} \frac{\Delta y}{v}
$$

where $\Delta T$ is the temperature change corresponding to the position change $\Delta y$. This result shows the inverse dependence of $\Delta T$ on the inflow velocity and the direct dependence on the width of the shear zone. The rate of 


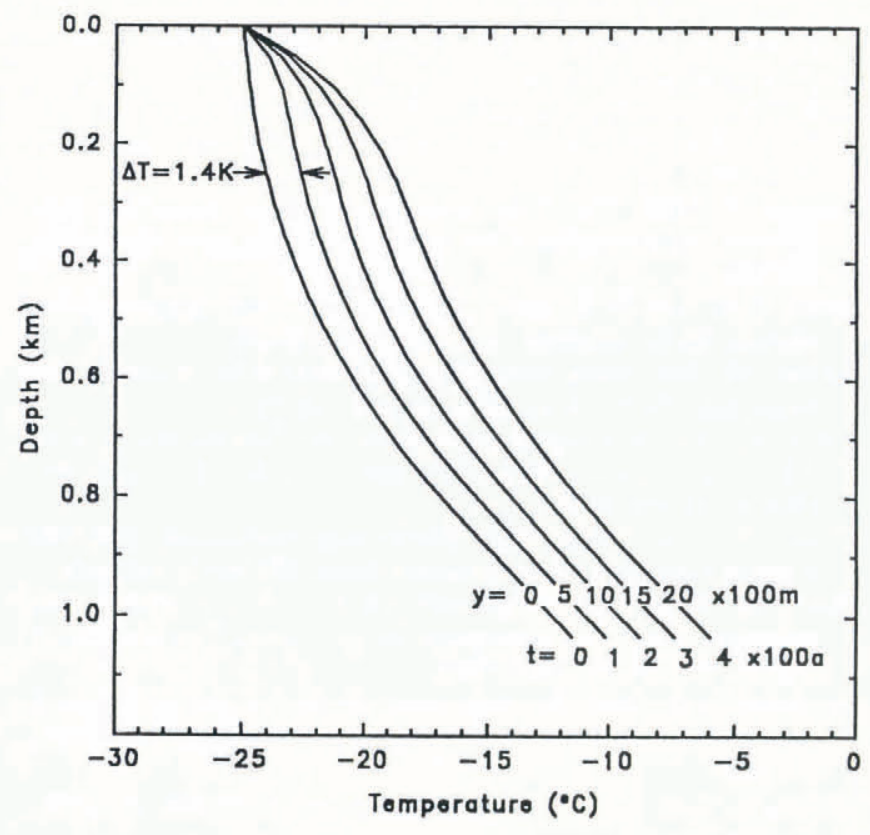

Fig. 7. Temperature in the margin as a function of distance $y$ from the outer edge for a constant transverse velocity $v$ of $5 \mathrm{~m} \mathrm{a}^{-1}$. The corresponding residence time $t$ of the ice in the margin is also shown.

increase of temperature is about $1.4 \mathrm{~K}$ per 100 years of residence time, or per $500 \mathrm{~m}$ at an average inflow rate of $5 \mathrm{~m} \mathrm{a}^{-1}$. The total increase at a depth of $250 \mathrm{~m}$ or more is about $5.6 \mathrm{~K}$ for a $2 \mathrm{~km}$ wide margin. At lower inflow rates $\left(v \sim 1-2 \mathrm{~m} \mathrm{a}^{-1}\right)$, which are probably more representative of the marginal part of the Upstream B profile, this increase could approach $15 \mathrm{~K}$. Vertical advection and conduction will affect the temperature increase to depths of $\dot{b t} \sim 80 \mathrm{~m}$ and $\sqrt{4 \kappa t} \sim 250 \mathrm{~m}$, respectively, for a transit time $t$ through the margin of $400 \mathrm{a}$. Conduction dominates. The effect is seen in Figure 7.

Ideally, Equation (14) should be integrated across the shear zone to take the variation in $\dot{\epsilon}_{x y}$ and $\tau_{x y}$ into account. In addition, such an integration would incorporate the changing transverse velocity experienced by a parcel of ice traveling along a convergent flowline which may have started many tens of kilometers upstream at the ice sheet; the limited upstream extent of the Dragon (Fig. 1a) may be a factor in this situation. Under these conditions, the value of $\Delta T$ given by Equation (14) should be an upper bound. It is worth noting that the predicted temperature at some distance above the bed would be affected by basal heating if this source were taken into account. The predicted temperature at these depths would also change if a more realistic basal boundary condition were used. Considering the nearsurface complications already discussed, Equation (14) should apply best at intermediate depths.

This approximate analysis shows that substantial heating may occur within the margin under steady-state conditions. This heating will cause a softening of the ice found in the margins through the thermally activated flow-law parameter $A$. Increasing the temperature by $5-$ $10 \mathrm{~K}$ could lead to an effective enhancement factor of $2-5$, which would be imposed upon any enhancement arising due to preferred fabric development. The values of $E$ shown in Figures $3 \mathrm{~b}$ and 6 incorporate all possible sources of enhancement.
It is interesting to note that the margins of Jakobshavns Isbræ, a fast-moving ice stream in Greenland, are a few degrees warmer than the center line (Echelmeyer and others, 1992). The in-flow velocity is large there but the viscous-heating term is also very large.

\section{CONGLUSIONS}

The magnitude and shape of transverse-velocity profiles have been used to investigate the roles of the shear margins and of the bed in the force balance of Ice Stream B. We find that the restraint supplied by marginal drag is equal to or somewhat greater than that of the integrated basal friction.

At the bed, there must be a weak, deformable layer and/or there must be greatly enhanced basal sliding. This result is constrained by the relatively large center-line speed and the small driving stress. While the basal shear stress at Upstream B must be low, it must, on average, be greater than the measured shear strength of basal till recovered by Engelhardt and others (1990). A distribution of saturated till and bedrock protrusions or other "sticky" spots across the bed could lead to the required basal shear stress.

Given unenhanced ice rheology, there is no physically reasonable distribution of basal shear stress which, by itself, can lead to the observed profiles of velocity. The curvature of the profiles requires a softening of ice in the marginal zones of both Upstream and Downstream B.

A good fit to the observed velocity is obtained by models with the following properties: a weak, deformable basal layer whose properties do not vary laterally, except possibly at the margin; constant, unenhanced ice rheology in the central part of the ice stream; soft ice within the marginal shear zones, with an enhancement factor equal to about 10 or 12 within the chaotic zone; and somewhat stiffer ice $(E=2-3)$ and/or increased basal drag in the slow-moving ice outside the ice stream.

These results depend critically on the detailed structure of the decrease in speed within the marginal zone. Of course, the distribution of $E$ and basal shear stress is not unique. This is because there is a trade-off between basal friction and softening of the overlying ice. This trade-off is limited, however, because no amount of decrease in $\tau_{\mathrm{b}}$ can eliminate the requirement that there is soft ice at the margins.

These conclusions may possibly apply to other ice streams for which the driving stresses are small and the surface speeds are high. The enhanced flow properties of marginal ice were first suggested by Hughes (1975) to explain the general features of the Siple Coast ice streams. For an ice stream of fixed width, the lower the basal shear stress (i.e. the more deformable the bed or the greater the basal sliding), the greater the importance of the margins in the force balance. In the limiting case of a floating ice stream or ice shelf, the restraining force must come entirely from a combination of marginal drag and longitudinal stress gradients. For ice streams in which the driving stresses are larger, such as Jakobshavns Isbræ in Greenland, the basal shear stress need not be so small, because there is a high proportion of internal deformation within the ice (Echelmeyer and others, 1991). 
Strain heating in the margins may warm the ice significantly, as observed on Jakobshavns Isbræ, Greenland (Echelmeyer and others, 1992). The actual warming depends sensitively on the rate of convergence of cold ice into the ice stream from the ice sheet, because this determines the time that a parcel of ice is heated within the marginal zone. For values of the transverse velocity and viscous-heat dissipation at the margins typical of our final models, this heating amounts to about a $3-10 \mathrm{~K}$ increase in ice temperature. This temperature increase will lead to an additional softening of the marginal ice through the thermally activated flow-law parameter $A$. Therefore, strain heating in the margins may play an important role in ice-stream dynamics.

\section{ACKNOWLEDGEMENTS}

Financial support for this project was through the U.S. National Science Foundation grant DPP-8716604. We benefited from constructive comments made by $\mathrm{R}$. Bindschadler, W. Budd, D. MacAyeal and C. Raymond. The manuscript was prepared by J. Ballew and P. Babcock, and the figures were drafted by J. DeMallie.

\section{REFERENGES}

Alley, R. B., D. D. Blankenship, C. R. Bentley and S. T. Rooney. 1987. Till beneath Ice Stream B. 3. Till deformation: evidence and implications. 7. Geophys. Res., 92(B9), 8921-8929.

Bentley, C. R. 1987. Antarctic ice streams: a review. F. Geophys. Res., 92(B9), 8843-8858.

Bindschadler, R. A., S. N. Stephenson, D. R. MacAyeal and S. Shabtaie. 1987. Ice dynamics at the mouth of Ice Stream B, Antarctica. F. Geophys. Res., 92(B9), 8885-8894.

Blankenship, D. D., C. R. Bentley, S. T. Rooney and R. B. Alley. 1987. Till beneath Ice Stream B. 1. Properties derived from seismic travel times. J. Geophys. Res., 92(B9), 8903-8911.

Clarke, T.S. and K. Echelmeyer. 1989. High resolution seismic reflection profiles across Jakobshavns Isbræ, Greenland. EOS, 70(43), 1080.

Echelmeyer, K. 1983. Response of Blue Glacier to a perturbation in ice thickness: theory and observation. (Ph.D. thesis, California Institute of Technology.)

Echelmeyer, K., R. Wade and A. Iken. 1991. Mechanisms of ice stream motion: Jakobshavns Isbre, Greenland. EOS, 72(44), 150.

Echelmeyer, K., W. D. Harrison, T. S. Clarke and C. Benson. 1992. Surficial glaciology of Jakobshavns Isbrr, West Greenland: Part II. Ablation, accumulation and temperature. f. Glaciol., 38(128), 169-181.

Engelhardt, H., N. Humphrey, B. Kamb and M. Fahnestock. 1990.
Physical conditions at the base of a fast moving Antarctic ice stream. Science, 248(4951), 57-59.

Frolich, R. M. and C. S. M. Doake. 1988. Relative importance of lateral and vertical shear on Rutford Ice Stream, Antarctica. Ann. Glaciol., 11, 19-22.

Hughes, T. 1975. The West Antarctic ice sheet: instability, disintegration, and initiation of ice ages. Rev. Geophys. Space Phys., 13(4), 502-526.

Jacka, T.H. and W.F. Budd. 1989. Isotropic and anisotropic flow relations for ice dynamics. Ann. Glaciol., 12, 81-84.

Jackson, M. 1991. Repeat aerial photogrammetry of Ice Stream B, West Antarctica. (M.Sc. thesis, Ohio State University.)

Kamb, B. 1991. Rheological nonlinearity and flow instability in the deforming bed mechanism of ice stream motion. 7. Geophys. Res., 96(B10), 16,585-16,595.

Kamb, W. B. and 7 others. 1985. Glacier surge mechanism: 1982-1983 surge of Variegated Glacier, Alaska. Science, 227(4686), 469-479.

MacAyeal, D. R. 1989. Large-scale ice flow over a viscous basal sediment: theory and application to Ice Stream B, Antarctica. F. Geophys. Res., 94(B4), 4071-4087.

MacAyeal, D. R. 1992. The basal stress distribution of Ice Stream E, Antarctica, inferred by control methods. F. Geophys. Res., 97(B1), 595-603.

McIntyre, N.F. 1985. The dynamics of ice-sheet outlets. F. Glaciol., 31(108), 99-107.

Nye, J.F. 1965. The flow of a glacier in a channel of rectangular, elliptic or parabolic cross-section. F. Glaciol., 5(41), 661-690.

Paterson, W. S. B. 1981. The physics of glaciers. Second edition. Oxford, etc., Pergamon Press.

Retzlaff, R., N. Lord and C. R. Bentley. 1993. Airborne-radar studies: Ice Streams A, B and C, West Antarctica. F. Glaciol., 39(133), 495506.

Shabtaie, S. and C.R. Bentley. 1987. West Antarctic ice streams draining into the Ross Ice Shelf: configuration and mass balance. $\mathcal{F}$. Geophys. Res., 92(B2), 1311-1336.

Shabtaie, S. and C. R. Bentley. 1988. Ice-thickness map of the West Antarctic ice streams by radar sounding. Ann. Glaciol., 11, 126-136.

Shabtaie, S., I. M. Whillans and C. R. Bentley. 1987. The morphology of Ice Streams A, B, and C, West Antarctica, and their environs. 7 . Geophys. Res., 92(B9), 8865-8883.

Van der Veen, C.J. and I. M. Whillans. 1989. Force budget: II. Application to two-dimensional flow along Byrd Station Strain Network, Antarctica. F. Glaciol., 35(119), 61-67.

Vornberger, P.L and I. M. Whillans. 1986. Surface features of Ice Stream B, Marie Byrd Land, West Antarctica. Ann. Glaciol., 8, $168-170$.

Vornberger, P. L. and I. M. Whillans. 1990. Crevasse deformation and examples from Ice Stream B, Antarctica. F. Glaciol., 36(122), 3-10.

Whillans, I. M. 1987. Force budget of ice sheets. In Van der Veen, J. and J. Oerlemans, eds. Dynamics of the West Antarctic ice sheet. Dordrecht, etc., D. Reidel Publishing Co., 17-36.

Whillans, I. M., J. Bolzan and S. Shabtaie. 1987. Velocity of Ice Streams B and C, Antarctica. F. Geophys. Res., 92(B9), 8895-8902.

Whillans, I. M., M. Jackson and Y.-H. Tseng. 1993. Velocity pattern in a transect across Ice Stream B, Antarctica. f. Glaciol., 39(133), $562-572$.

The accuracy of references in the text and in this list is the responsibility of the authors, to whom queries should be addressed. 